\title{
Perennial kales: collection rationalization and genetic relatedness to other Brassica oleracea crop types
}

\author{
Robbert van Treuren · Noor Bas
}

Received: 26 September 2006/ Accepted: 26 February 2007 / Published online: 4 May 2007

(C) Springer Science+Business Media B.V. 2007

\begin{abstract}
Perennial kale is a rare leafy vegetable and forage crop that is mainly vegetatively propagated and therefore expensive to conserve ex situ. A genebank collection of 47 perennial kales and 34 reference samples from the main Brassica oleracea crop types were characterized with seven microsatellite markers in order to verify potential redundancies and to obtain more insight in the position of perennial kales within $B$. oleracea. Based on the obtained results and on data from previous studies, the collection was reduced with $49 \%$ to 24 perennial kales. Considering this level of reduction, it was estimated that the investments made for the final verification by microsatellite analysis are returned after only 4-year time. A principal coordinate plot clearly separated the perennial kales from the other crop types of $B$. oleracea, except in one case. This deviating accession of vegetatively preserved perennial kale clustered closely together with the single seed-preserved accession of perennial kale included in the study. These two accessions occupied an intermediate position between the group of vegetatively propagated perennial kales and the group of seed-propagated Brassica accessions, suggesting a hybridization background with another $B$. oleracea
\end{abstract}

R. van Treuren $(\bowtie) \cdot$ N. Bas

Centre for Genetic Resources, The Netherlands, Wageningen University and Research Centre, P.O. Box 16, 6700 AA Wageningen, The Netherlands

e-mail: robbert.vantreuren@wur.nl crop type. The microsatellite study demonstrated a close genetic relationship among the investigated perennial kales and their unique position within $B$. oleracea.

Keywords Brassica oleracea - Microsatellites · Perennial kale $\cdot$ Redundancy $\cdot$ Taxonomy

\section{Introduction}

Perennial kale (Brassica oleracea L. var. ramosa DC.) is considered one of the first domesticated crops of wild kale. This leafy vegetable and forage crop shows a strongly reduced flowering ability, which is generally believed to have resulted from a long and intensive selection process for high-leaf production (Zeven et al. 1989). In the past, perennial kale has probably been widely distributed in Western Europe, but the crop has gradually declined in occurrence in this area. Nowadays perennial kale is a rare crop that can still be found in parts of Ireland, Scotland, The Netherlands, Belgium, France, Germany, and Portugal. Outside Europe, the crop has been observed in Brazil, Haiti, and Ethiopia (Zeven et al. 1996). It has been suggested that perennial kales occupy a unique position within B. oleracea (Zeven et al. 1996), but no experimental studies to investigate the genetic relatedness to other crop types within the species have been reported. 
Perennial kales are ex situ conserved in at least two locations. At the Centre for Genetic Resources, The Netherlands (CGN), a collection of 47 perennial kales originating from France, Belgium, and The Netherlands is maintained. Because of the reduced flowering ability, this collection is kept in vivo, requiring vegetative propagation on a continuous basis. In addition, CGN possesses a single seed accession of perennial kale that probably has originated from cross pollination between perennial kale and another $B$. oleracea crop type (I. Boukema, personal communication). A duplicate of CGN's vegetative collection, extended with a few Portuguese accessions, is maintained at the Leibniz Institute of Plant Genetics and Crop Plant Research Gatersleben (IPK) in Germany (Zeven et al. 1998).

Compared to seed collections that are stored in freezer facilities and that require seed multiplication only once every 20-50 years, in vivo collections are quite expensive to maintain. Storage and regeneration of CGN's vegetative collection of perennial kales required $\sim 2,800$ euros in 2004. A more efficient conservation may be achieved by eliminating duplicates, but the economical benefits depend on the investments necessary to identify redundancies and the savings resulting from a reduced collection (van Treuren et al. 2001, 2004; van Treuren and van Hintum 2003).

Based on the mainly vegetative reproduction, it has been suggested that genetic variation in perennial kale may be rather limited. This hypothesis was confirmed by isozyme, RAPD, cytological and morphological investigations (Zeven et al. 1996, 1998) and suggested that CGN's vegetative perennial kale collection could be reduced to 15 accessions. However, verification of these results with high-resolution techniques was suggested before taking any final decisions about rationalization (Zeven et al. 1998). In the present study, microsatellite markers were used to characterize the collection. Due to their high level of polymorphism, microsatellites are informative markers that can be used for many population genetic purposes, ranging from the individual level (e.g., clone and strain identification) to closely related species (Queller et al. 1993; Jarne and Lagoda 1996). The microsatellite data were analyzed in coherence with the existing data from previous studies, aiming at the identification, and elimination of redundancies. Furthermore, the microsatellite data obtained for perennial kales were compared to those of a reference set of accessions representing the main crop types of CGN's B. oleracea collection in order to obtain more insight in the position of perennial kales within this species.

\section{Material and methods}

Study material

CGN's entire collection of 47 vegetative perennial kale accessions was included in the present study. In previous studies, these accessions have been examined for chromosome number (Zeven et al. 1989), isozyme variation, leaf color pigmentation, and flowering behavior in three different years (Zeven et al. 1996), RAPD variation and morphological characteristics (Zeven et al. 1998). Based on these studies, a main clone type consisting of 20 accessions could be distinguished, whereas three other clone types included 8, 5, and 3 accessions, respectively (Table 1). Apart from two accessions that could not be classified because of missing values, the other clone types were represented by only a single accession. The majority of accessions deviated from the main type by only a single character. Accession 29 was the most deviating accession from the main clone type as four of the six characters were different (Table 1). Based on this classification, 32 accessions were considered potential redundancies. In addition to the group of 47 vegetative perennial kales, 34 reference accessions were included in the study, comprising all the main crop types from CGN's seed collection of B. oleracea (Table 2). These references were chosen based on wide diversity and consisted of 1-4 accessions per crop type. Group $M$ was represented by CGN's single seed accession of perennial kale. This accession was received as a seed sample from the Foundation of Plant Breeding (Wageningen, The Netherlands). It has been suggested that this seed sample has resulted from cross pollination between perennial kale and another B. oleracea crop type (I. Boukema, personal communication). Despite several efforts, seed multiplication of this accession using CGN's standard regeneration protocol for Brassica has so far been unsuccessful. 
Table 1 Classification of the 47 vegetative perennial kale accessions based on morphological, cytological, and marker data (reconstructed from Zeven et al. 1996, 1998)

\begin{tabular}{lllllll}
\hline Accession code $^{\mathrm{a}}$ & RAPD profile & Isozyme profile & Flowering & Pigmentation & Morphotype & Chromosomes \\
\hline $6,12,17,19,23,27,32,34,36,37,39,41$, & A & A & No & Purple & 1 & 18 \\
$45,49,57,58,60,61,62,63$ & & & & & \\
64 & A & A & No & Purple & $?$ & $?$ \\
$1,7,18,26,28,40,43,46$ & A & A & No & Purple & 1 & 36 \\
$13,52,54,56,59$ & A & A & No & Purple & 2 & 18 \\
$5,38,44$ & A & A & No & Green & 1 & 18 \\
65 & A & A & No & Green & $?$ & $?$ \\
22 & A & A & Yes & Purple & 1 & 18 \\
50 & A & C & No & Purple & 1 & 18 \\
8 & A & A & Yes & Purple & 2 & 18 \\
9 & A & A & Yes & Purple & 3 & 18 \\
15 & D & A & No & Purple & 5 & 18 \\
51 & A & A & No & Green & 2 & 36 \\
24 & A & B & Yes & Purple & 1 & 36 \\
25 & B & D & Yes & Purple & 1 & 18 \\
29 & C & E & Yes & Purple & 7 & 18 \\
\hline
\end{tabular}

The main clone type is presented in the first row. The other accessions are classified according to the number of deviating characteristics (grey shaded cells) from the main clone type

a Accession codes are identical to those used by Zeven et al. $(1996,1998)$

Molecular analysis

From a single individual of each accession $\sim 100 \mathrm{mg}$ of fresh leaf tissue was collected, immediately frozen in liquid nitrogen and stored at $-80{ }^{\circ} \mathrm{C}$ until use. Total genomic DNA was extracted from freeze-dried leafs using a combination of the methods described by Fulton et al. (1995) and the DNeasy 96 Plant Kit (Qiagen, Westburg, The Netherlands). Microsatellites were amplified by multiplex-PCR in two sets, including, respectively, the loci BoD003 (FAM), BoD006 (NED) and BoD021 (HEX), and the loci BoD005 (NED) BoD010 (HEX), BoD023 (NED), and BoE014 (FAM). These markers were developed at the Business Unit Biodiversity and Breeding of Wageningen University and Research Centre (Wageningen, The Netherlands). PCR was performed using a MJ PTC200 thermocycler and carried out in $20 \mu$ reaction volumes containing $10 \mathrm{ng}$ genomic DNA, 2 pmol of each primer, $100 \mu \mathrm{M}$ of each dNTP, $10 \mathrm{mM}$ Tris-HCL pH 9.0, $20 \mathrm{mM}\left(\mathrm{NH}_{4}\right)_{2} \mathrm{SO}_{4}, 0.01 \%$ Tween 20, $1.5 \mathrm{mM} \mathrm{MgCl}_{2}$, and $0.4 \mathrm{U}$ Goldstar Taq DNA polymerase (Eurogentec, Maastricht, The Netherlands). The amplification profile consisted of an initial cycle of $94{ }^{\circ} \mathrm{C}$ for $3 \mathrm{~min}$, followed by 30 cycles of $94{ }^{\circ} \mathrm{C}$ for $30 \mathrm{~s}, 50^{\circ} \mathrm{C}$ for $30 \mathrm{~s}$, and $72{ }^{\circ} \mathrm{C}$ for $120 \mathrm{~s}$, and a final extension cycle at $72{ }^{\circ} \mathrm{C}$ for $3 \mathrm{~min}$. Fluorescently labeled PCR products were separated by capillary electrophoresis using an ABI Prism 3700 DNA analyzer (Applied Biosystems, Foster City, CA, USA). Fragment sizes and peak areas were determined automatically using the GENESCAN analysis software (release 1.13700 software, Applied Biosystems) and further processed with the software package Genotyper, Version 3.5 NT (Perkin-Elmer, Foster City, CA, USA).

\section{Data analysis}

Microsatellite alleles were denoted based on the observed number of base pairs of the PCR products. Genetic relationships between accessions were visualized by Principal Coordinates (PCO) using the software package Genstat (release 8.11). For this purpose, similarity values were calculated based on Jaccard's coefficient after transforming the microsatellite data to binary scores for allele absence and presence. 
Table 2 Overview of the 34 reference accessions selected from CGN's B. oleracea seed collection

\begin{tabular}{|c|c|c|c|}
\hline Group & Crop type & Accession name & Accession number \\
\hline \multirow[t]{2}{*}{ A } & \multirow[t]{2}{*}{ Pointed headed cabbage } & Filderkraut & 7069 \\
\hline & & Sappemeerse-group 1 & 14050 \\
\hline \multirow[t]{3}{*}{ B } & \multirow[t]{3}{*}{ Savoy cabbage } & Antwerpse Putjes & 7097 \\
\hline & & Langedijker Bewaargele-group 1 & 7110 \\
\hline & & Schelk-Sel. Willems & 7121 \\
\hline \multirow[t]{2}{*}{$\mathrm{C}$} & \multirow[t]{2}{*}{ Red cabbage } & Langedijker Bewaar-Graag group 1 & 11043 \\
\hline & & Kissendrup-Piru & 11165 \\
\hline \multirow[t]{2}{*}{$\mathrm{D}$} & \multirow[t]{2}{*}{ White cabbage } & Langedijker Bewaar-Taai group 1 & 7054 \\
\hline & & Tai-on No. 3 & 17273 \\
\hline \multirow[t]{2}{*}{$\mathrm{E}$} & \multirow[t]{2}{*}{ Brussels sprouts } & Roem van Barendrecht-Sel. Groeneboom group 1 & 11025 \\
\hline & & Groninger-Stiekema & 14071 \\
\hline \multirow[t]{3}{*}{$\mathrm{F}$} & \multirow[t]{3}{*}{ Borecole } & Sel. de Vries & 11143 \\
\hline & & Westerwoldse Grove & 15120 \\
\hline & & Verheul & 15121 \\
\hline \multirow[t]{2}{*}{ G } & \multirow[t]{2}{*}{ Cauliflower } & Selfblanche-Brendo & 11114 \\
\hline & & Walcheren Winter-Armado Tardo & 15129 \\
\hline \multirow[t]{2}{*}{$\mathrm{H}$} & \multirow[t]{2}{*}{ Broccoli } & Brimo & 18473 \\
\hline & & Primo & 18474 \\
\hline \multirow[t]{2}{*}{ I } & \multirow[t]{2}{*}{ Kohlrabi } & Blauwe Spek & 7136 \\
\hline & & Castor & 7137 \\
\hline \multirow[t]{2}{*}{$\mathrm{J}$} & \multirow[t]{2}{*}{ Tronchuda } & Tronchuda Portuguese & 17283 \\
\hline & & Tronchuda Portuguese & 20193 \\
\hline \multirow[t]{2}{*}{ K } & \multirow[t]{2}{*}{ Marrowstem kale } & Hoge Groene & 15123 \\
\hline & & Witte Giant Marrow & 15124 \\
\hline \multirow[t]{2}{*}{$\mathrm{L}$} & \multirow[t]{2}{*}{ Chinese kale } & Kailan & 14038 \\
\hline & & Golden & 14044 \\
\hline M & Perennial kale & & $861651^{\mathrm{a}}$ \\
\hline \multirow[t]{4}{*}{$\mathrm{N}$} & \multirow[t]{4}{*}{ Other kales } & Westfalische Furchenkohl & 11125 \\
\hline & & Choux de Jalhay & 14079 \\
\hline & & Butzo & 14111 \\
\hline & & Galega Lisa & 20191 \\
\hline \multirow[t]{3}{*}{$\mathrm{O}$} & \multirow[t]{3}{*}{ Wild } & Brassica L. & 7149 \\
\hline & & Brassica montana & 18472 \\
\hline & & Brassica oleracea & 18947 \\
\hline
\end{tabular}

\footnotetext{
${ }^{a}$ Receipt number instead of accession number
}

\section{Results}

Diversity among perennial kales

Within the group of perennial kales, 21 different microsatellite alleles were observed and seven different multilocus marker profiles could be distinguished among the vegetative accessions. Identical microsatellite profiles were observed for a group of
38 accessions, while accessions 38, 50, 58, 64, and 65 differed from this main type by a single marker (Table 3). Accession 29 showed the largest deviation from the main microsatellite profile as different scores were observed for five of the seven markers. Unfortunately, accessions 1 and 25 could not be classified because of missing values. No data were obtained from accession 5, probably due to poor DNA quality. The microsatellite data indicated a 
Table 3 Classification of the 47 vegetative perennial kale accessions based on seven microsatellite markers

\begin{tabular}{|c|c|c|c|c|c|c|c|}
\hline Accession code ${ }^{\mathrm{a}}$ & BoE014 & BoD006 & BoD021 & BoD023 & BoD010 & BoD003 & BoD005 \\
\hline $\begin{array}{c}6,7,8,9,12,13,15,17,18,19,22,23, \\
24,26,27,28,32,34,36,37,39,40, \\
41,43,44,45,46,49,51, \\
52,54,56,57,59,60,61,62,63\end{array}$ & $174 / 187$ & $240 / 273$ & 197 & $200 / 203$ & $250 / 258$ & 265 & 142 \\
\hline 25 & $174 / 187$ & $240 / 273$ & 197 & $?$ & $?$ & 265 & $?$ \\
\hline 50 & $174 / 187$ & $240 / 273$ & 197 & $200 / 203$ & $250 / 258$ & 265 & $127 / 142$ \\
\hline 64 & $174 / 187$ & $240 / 273$ & 197 & $200 / 203$ & $250 / 258$ & 265 & $142 / 145$ \\
\hline 1 & $?$ & $240 / 273$ & 197 & $200 / 203$ & $250 / 258$ & 265 & $142 / 145$ \\
\hline 38 & $174 / 187$ & $240 / 273$ & 197 & $200 / 203$ & $250 / 258$ & $250 / 265$ & 142 \\
\hline 65 & $174 / 187$ & $240 / 273$ & 197 & $200 / 203$ & $250 / 258$ & $265 / 268$ & 142 \\
\hline 58 & $174 / 187$ & $240 / 273$ & 197 & $200 / 203$ & $250 / 261$ & 265 & 142 \\
\hline 29 & $174 / 187$ & $240 / 255$ & $197 / 201$ & $200 / 209$ & $247 / 250$ & $265 / 280$ & 142 \\
\hline 861651 & $174 / 187$ & 255 & $197 / 201$ & $200 / 209$ & 250 & $265 / 280$ & 142 \\
\hline
\end{tabular}

Microsatellite alleles are denoted by the observed number of base pairs of the PCR product. The main clone type is presented in the first row. The other accessions are classified according to the number of deviating microsatellite scores (grey shaded cells) from the main clone type. The single perennial kale accession of CGN's seed collection is presented in the last row for comparison

${ }^{\text {a }}$ No microsatellite scores were obtained for accession 5

close genetic relationship within the group of vegetative perennial kales, with the exception of accession 29.

The group of 38 accessions showing identical microsatellite profiles basically comprised the three main potential duplication groups presented in Table 1. Out of the total number of 32 potential redundancies identified in the previous studies concordance was found for 28 accessions (88\%) based on the microsatellite data, indicating that the collection of 47 vegetative perennial kales could be reduced to 19. This level of reduction was probably slightly underestimated due to the occurrence of missing values.

\section{Relationship with other Brassica oleracea crop types}

Among the total number of 81 investigated accessions, a total of 72 microsatellite alleles were observed, ranging from 3 for marker BoD023 to 17 for marker BoD003. Allele 273 of microsatellite BoD006 and allele 250 of BoD010 that were common to perennial kales were absent from the other $B$. oleracea crop types examined. Other alleles observed in perennial kales ranged from rare to common within the group of other B. oleracea crop types. Perennial kale accession 861651 from CGN's seed collection displayed a remarkable resemblance with perennial kale accession 29 as they shared most of the alleles that were not seen in the other perennial kales (Table 3). A PCO plot separated all but one of the vegetative perennial kales from the other $B$. oleracea crop types on the first principal axis that explained $26.4 \%$ of the total variation (Fig. 1). Together, the two principal axes explained $33.7 \%$ of the total variation observed. Accession 29 clustered closely together with accession 861651 (indicated by ' $\mathrm{M}$ ', in Fig. 1) and occupied an intermediate position between the group of vegetatively propagated perennial kales and the group of seed-propagated Brassica accessions. Results of the PCO analysis were in line with the earlier suggestions that perennial kales occupy a unique position within $B$. oleracea and that seed accession 861651 has a hybridization background with another $B$. oleracea crop type.

\section{Discussion}

The vegetative accessions of perennial kale showed a close genetic relationship and suggested a common origin. Identical fingerprinting profiles were observed for the majority of accessions, while deviating accessions were different for only a single microsatellite marker, with the exception of accession 29. 
Fig. 1 Principal Coordinate plot using the microsatellite data of CGN's rationalized in vivo collection of perennial kales (filled circle) and those of the reference samples from CGN's seed collection of $B$. oleracea accessions (A-O, see Table 2). The percentage of variation explained by the axes is presented in parentheses in the axis legend



This accession has probably a hybrid background with another $B$. oleracea crop type as it showed a high similarity with the investigated seed accession of perennial kale. Moreover, these two accessions were found intermediate between the group of other perennial kales and the group of other $B$. oleracea crop types in a PCO plot. Variation observed for the other perennial kales may have resulted from mutational events during the annual vegetative propagation. Variation between the perennial kale accessions was slightly higher based on previous characterization data (Table 1). However, doubling of chromosome number has resulted from autotetraploidy (Zeven et al. 1989), which is not necessarily accompanied by novel variation. Furthermore, morphological characters may be influenced by environmental variation. For example, leaf color pigmentation in perennial kale is highly affected by stress factors (personal observations), while the flowering behavior was found to vary between years and between different vegetative cuts of the same accession (Zeven et al. 1996).

Rationalization of germplasm collections is an important aspect of plant genetic resources management because of genetic and economic considerations
(Engels and Visser 2003). Molecular marker technologies are thereby increasingly applied to identify or verify redundancies (Spooner et al. 2005). Combined with cytological, morphological, and marker data from previous investigations (Zeven et al. 1996, 1998), the present microsatellite study indicated that CGN's vegetative collection of 47 perennial kale accessions could be reduced to 19 (40\%). This was even considered a conservative number because a few accessions displaying missing values were regarded as different, while no distinction was observed from other accessions based on the available scores. In addition to the group of 19 accessions it was decided to maintain five redundant accessions in order to represent the main clone types by multiple accessions for safety reasons (accession 17, 26, 27, and 59) and because of differences in country of origin (accession 60). Consequently, the collection was reduced with $49 \%$ to 24 accessions (Table 4 ).

Apart from an improved collection composition, rationalization may also result in economical benefits. However, whether return of investments can be expected depends on various factors, including the costs to maintain accessions, the costs to identify redundancies and the extent to which a collection can 
Table 4 Main passport data of CGN's reduced collection of 24 in vivo maintained perennial kales

\begin{tabular}{|c|c|c|c|c|}
\hline Accession code & Receipt number & Name & Collection site & Country of origin \\
\hline 1 & 040730 & Crutzen & Mechelen & The Netherlands \\
\hline 5 & 040731 & Huydts & Hulsberg & The Netherlands \\
\hline 6 & 040732 & Spiga & Benzenrade & The Netherlands \\
\hline 7 & 040733 & Dolmans & Smeermaas & Belgium \\
\hline 8 & 040734 & Debets & Euverem & The Netherlands \\
\hline 9 & 040735 & Hagenstein & Epen & The Netherlands \\
\hline 13 & 040736 & Crutzen & Vaals & The Netherlands \\
\hline 15 & 040737 & Huver & Heerlen & The Netherlands \\
\hline 17 & 040738 & Kramer & Sittard & The Netherlands \\
\hline 22 & 040739 & Ruyl & Elsloo & The Netherlands \\
\hline 24 & 040740 & Starink & Geleen & The Netherlands \\
\hline 25 & 040741 & Tillie & Geulle & The Netherlands \\
\hline 26 & 040742 & Zee & Born & The Netherlands \\
\hline 27 & 040743 & Zee & Born & The Netherlands \\
\hline 29 & 040744 & Zwart & Beek (Limburg) & The Netherlands \\
\hline 38 & 040745 & Peeters & Horn & The Netherlands \\
\hline 44 & 040746 & Giesberts & Beegden & The Netherlands \\
\hline 50 & 040747 & Hendriks & Haelen & The Netherlands \\
\hline 51 & 040748 & Ramakers & Echt & The Netherlands \\
\hline 58 & 040749 & Kleintjes & Stein & The Netherlands \\
\hline 59 & 040750 & Silvertand & Wijlre & The Netherlands \\
\hline 60 & 040751 & Dirix & Argeneuil/Brest & France \\
\hline 64 & 040752 & van Mourik & Maastricht & The Netherlands \\
\hline 65 & 040753 & Penning & Sittard & The Netherlands \\
\hline
\end{tabular}

be reduced (van Treuren et al. 2001, 2004; van Treuren and van Hintum 2003). The costs to maintain the collection of 47 vegetative perennial kales are $\sim 2,800$ euros per year, while the total costs for the microsatellite study were 5,479 euros. Based on a reduction of the collection with $49 \%$, this means that the investments made for the final verification by microsatellite analysis will be returned in only 4-year time.

In addition to rationalization, the maintenance of the perennial kale collection could also be made more economical in case seed propagation could be realized. Despite the existence of a perennial kale seed accession and the occasional flowering of perennial kale, this does not seem a realistic option. Several attempts to obtain seeds from flowering plants kept in vivo and to regenerate CGN's perennial kale seed accession have failed so far. The close genetic relationship observed among the investigated accessions may possibly indicate fixation of potential incompatibility genes that hamper seed propagation. This may not have played a role for the single seed accession of perennial kale that was shown to have likely resulted from hybridization between perennial kale and another $B$. oleracea crop type.

A clear separation between perennial kales and the other B. oleracea crop types was observed using PCO analysis, but within the latter group no clear differentiation was found. Considering the high levels of variation that have been reported within and between B. oleracea cultivar groups (Figdore et al. 1988), larger sample sizes may increase the accuracy of genetic diversity estimates for the different crop types. Nevertheless, so far the microsatellite data supported the earlier suggestion of Zeven et al. (1996) that perennial kales occupy a unique position within B. oleracea. 
Acknowledgments The authors are grateful to Clemens van de Wiel, Paul Arens, and Gerda Uenk-Stunnenberg for their involvement in the experimental part of the study and to Anton Zeven, Klaus Dehmer, and two anonymous reviewers for their comments on an earlier version of the manuscript.

\section{References}

Engels JMM, Visser L (2003) A guide to effective management of germplasm collections IPGRI handbook for Genebanks No. 6. International Plant Genetic Resources Institute, Rome, Italy

Figdore SS, Kennard WC, Song KM, Slocum MK, Osborn TC (1988) Assessment of the degree of restriction fragment length polymorphism in Brassica. Theor Appl Genet 75:833-840

Fulton TM, Chunwongse J, Tanksley SD (1995) Microprep protocol for extraction of DNA from tomato and other herbaceous plants. Plant Mol Biol Rep 13:207-209

Jarne P, Lagoda PJL (1996) Microsatellites, from molecules to populations and back. Trends Ecol Evol 11:424-429

Queller DC, Strassmann JE, Hughes CR (1993) Microsatellites and kinship. Trends Ecol Evol 8:285-288

Spooner D, van Treuren R, de Vicente MC (2005) Molecular markers for Genebank management. IPGRI Technical Bulletin No. 10. International Plant Genetic Resources Institute, Rome, Italy van Treuren R, Magda A, Hoekstra R, van Hintum ThJL (2004) Genetic and economic aspects of marker-assisted reduction of redundancy from a wild potato germplasm collection. Genet Resour Crop Evol 51:277-290

van Treuren R, van Hintum ThJL (2003) Marker-assisted reduction of redundancy in germplasm collections: genetic and economic aspects. Acta Hort (ISHS) 623:139149

van Treuren R, van Soest LJM, van Hintum ThJL (2001) Marker-assisted rationalisation of genetic resources collections: a case study in flax using AFLPs. Theor Appl Genet 103:144-152

Zeven AC, Ramanna MS, Broeder M, Sawor Z, Waninge J (1989) Diploids and natural autotetraploids in the predominantly vegetatively propagated Brassica oleracea L. var. ramosa DC. and their cytology. Euphytica 41:59-64

Zeven AC, Suurs LCJM, Waninge J (1996) Diversity for enzymes, flowering behaviour and purple plant colour of perennial kale (Brassica oleracea L. var. ramosa DC.) in the Netherlands. In: Dias JS, Crute I, Monteiro AA (eds) Proceedings international symposium on Brassicas, pp $61-66$

Zeven AC, Dehmer KJ, Gladis T, Hammer K, Lux H (1998) Are the duplicates of perennial kale (Brassica oleracea $\mathrm{L}$. var. ramosa DC.) true duplicates as determined by RAPD analysis? Genet Resour Crop Evol 45:105-111 